\title{
Optimization on Loan-to-value Ratios of Port's Inventory Financing: Effects of Risk Aversion and Decision Preference
}

\author{
Shujie Diao ${ }^{1, a}$, Haibo Kuang ${ }^{* 2, b}$, Bin Meng ${ }^{3, c}$ \\ ${ }^{1}$ Collaborative Innovation Center for Transport Studies Dalian Maritime University Dalian, China \\ ${ }^{2}$ Collaborative Innovation Center for Transport Studies Dalian Maritime University Dalian, China \\ ${ }^{3}$ Collaborative Innovation Center for Transport Studies Dalian Maritime University Dalian, China
}

\begin{abstract}
Under inventory financing mode, port offers joint logistics and financial services to a capitalconstrained cargo-owner whose cargos are taken as collaterals. Port takes financial risk while gaining profit from both traditional logistics and derived financial services. This paper adopts Mean-CVaR criterion to formulate objective function and derive the equilibrium loan-to-value ratio. The Mean-CVaR model proposed in this article depicts risk-aversion attitude and decision preference of port under the uncertainty of collateral's demand. The result shows that there is a positive relation between decision preference and loan-to-value ratio. The growth in risk aversion attitude prompts port to act cautiously by reducing the loan-to-value ratio.
\end{abstract}

\section{Introduction}

As important transportation hub and logistics node, port has strong capacity of cargo collection and distribution, thus obtaining significant advantages in developing innovative logistics services such as inventory financing [1]. Nowadays, more and more port logistics companies provide financial supports for capital-constrained clients based on traditional logistics services including warehousing and transportation [2]. Some hub ports in China such as Tianjin Port, Qingdao Port and Dalian Port cooperate with banks to establish port logistics financial platform. One of the prerequisites for a loan is to take the cargos supervised by port as collaterals. The combination of traditional port logistics and financial services contributes to the expansion of port logistics service supply chain and increase of port's profit in the fierce market competition. Research on logistics finance including port inventory financing mode have gradually attracted attention. Wang and Ma (2009) elaborate the mechanism of warehousing financing in the ports grouphinterland logistics system [3]. They demonstrate that logistics financing can promote the development of large transportation hubs and enable banks to obtain higher returns with lower risks. Hofmann (2009) introduces the inventory financing issues from the perspective of logistics service providers [4]. Chen and Cai (2011) state that the 3PL (third party logistics) companies as well as the entire supply chain under logistics financing mode can attain higher profits than bank loan mode [5]. Huang et al. (2019) analyze the financial services offered by logistics companies like Maersk, and build a supply chain where the 3PL company provides loan services and is responsible for setting interest rates [2]. Wang et al. (2019) discuss the interest rate and freight rate decisions of a 3PL company

adsj8922@126.com, ${ }^{\mathrm{c} m e n g b i n f l y @ 163 . c o m ~}$

b*Corresponding author:khb@dlmu.edu.cn and measure the borrower's risk preference via meanstandard deviation [6].

Most of studies point out the crucial role warehousing and transportation companies have played in logistics finance, but few of them distinguish different risks faced by various kinds of logistics companies and then elaborate the entire process of logistics and the costs involved. In regard to the choice of financial decision variables, the adjustment space of interest rate is generally limited due to market regulations. In this case, loan-to-value ratio which is the ratio of the amount of the loan to the value of the collaterals shows more flexibility than interest rate [7]. The logistics companies are mostly considered as riskneutral in existing studies which indicate the limited application of risk measurements. There are different decision-making preferences towards risk-neutral expected profit and downside risks. Different risk aversion degree and different decision preference towards profit and downside risk could lead to different decision results [8].

To address the above issues, we build a piecewise profit function of port under inventory financing mode and introduce Mean-CVaR criterion which can reflect both risk aversion and decision preference to derive the equilibrium loan-to-value ratio. Based on the model, we display the influence of key factors on equilibrium decision.

\section{Modeling Framework}

We assume that port provides inventory financing services for cargo owners. The borrower applies for the loan taking cargos as collaterals which are stored and supervised by port. The port logistics company needs to evaluate the 
market value of the collaterals and set a reasonable loanto-value ratio.

The general parameters are denoted as follows. ${ }^{p}:$ The price of collaterals; ${ }^{q}$ : The quantity of collaterals; $w$ : The wholesale price of collaterals; $k$ : The residual value of unsold collaterals $(p>w>k) ; I_{r}$ : The interest rate charged by the port; ${ }^{I_{0}}$ : The interest rate paid by port to the bank; $T$ : The duration of pledge loan; $H$ : The port logistics services charge, covering cargo loading and unloading, handling, transshipment, transportation and onshore warehousing etc.; $C_{h}$ : The unit cost of port logistics service; $S$ : The pledge supervision charge; ${ }^{C_{s}}$ : The cost of supervision; $x$ : The random market demand for collaterals; $A$ : The maximum market demand of collaterals; $f(x)$ : The probability density function of the random variable ${ }^{x} ; F(x)$ : The distribution function of the random variable ${ }^{x}$. The decision variable is shown as below. $\lambda$ : The loan-to-value ratio.

At the end of the loan period, the borrower shall decide whether to pay the loan principal and interest ${ }^{\lambda w q}\left(1+I_{r} T\right)$, port logistics service charge ${ }^{H q}$, supervision fees $S q T$ in the light of the market value of collaterals. Therefore, the earning of the port falls into the following two situations: (1)The market value of the collaterals is not lower than the sum of loan principal, interest and service fee payable. At this point, the demand satisfies $x \geq\left[\lambda w q\left(1+I_{r} T\right)+H q+S q T-k q\right] /(p-k)$. Under the above condition, the borrower fulfills the contract, and the profit of port is $\lambda w q\left(I_{r}-I_{0}\right) T+\left(H-C_{h}\right) q+\left(S-C_{s}\right) q T$. (2)The market value of the collaterals is lower than the sum of loan principal, interest and logistics service fee payable. At this point, the demand satisfies $x<\left[\lambda w q\left(1+I_{r} T\right)+H q+S q T-k q\right] /(p-k)$. Under the above condition, the borrower chooses to default, and the profit of port is $(p-k) x+k q-\lambda w q\left(1+I_{0} T\right)-C_{h} q-C_{s} q T$. To sum up, the profit function of a risk-neutral port can be written as: $\pi(\lambda)= \begin{cases}(p-k) x+k q-\lambda w q\left(1+I_{0} T\right)-C_{h} q-C_{s} q T & 0 \leq x<Z_{0} \\ \lambda w q\left(I_{r}-I_{0}\right) T+\left(H-C_{h}\right) q+\left(S-C_{s}\right) q T & Z_{0} \leq x \leq A\end{cases}$

Where $Z_{0}=\left[\lambda w q\left(1+I_{r} T\right)+H q+S q T-k q\right] /(p-k), \quad$ which denotes the critical point of whether the borrower defaults or not.

Rockafellar and Uryasev (2000) proposed CVaR to measure the average value of financial asset below the quantile $\eta$ [9]. So, the CVaR of $\pi(\lambda)$ is expressed as $\operatorname{CVaR}_{\eta}[\pi(\lambda)]=E\left[\pi(\lambda) \mid \pi(\lambda) \leq \operatorname{VaR}_{\eta}(\pi(\lambda))\right]$, which can also be written as

$$
C_{V a R}[\pi(\lambda)]=\max _{v \in R}\left\{v+\frac{1}{\eta} E[\min (\pi(\lambda)-v, 0)]\right\} .
$$

$\mathrm{CVaR}$ has been applied in financial risk measurement for its superiority in consistency. However, it excludes the profit above this point, which will easily result in conservative behavior of decision maker. In response to this issue, the decision preference coefficient is introduced in the Mean-CVaR to ensure the comprehensive consideration of expected profit and CVaR [8][10]. The utility function is formulated as

$$
U[\pi(\lambda)]=\theta E[\pi(\lambda)]+(1-\theta) \operatorname{CVaR}_{\eta}[\pi(\lambda)], \theta \in(0,1) .
$$

$E[\pi(\lambda)]$ represents the expected profit and the confidence level $\eta(\eta \in(0,1])$ can be defined as risk aversion factor. The smaller the value of $\eta$ approaching 0 , the greater the degree of risk aversion. $\theta$ is decision preference coefficient describing the decision maker's trade-off between the expected profit and downside risk. The bigger value of $\theta$ is, the more optimistic decision maker will be with the pursuit of expected profit; the smaller value of $\theta$ is, the more pessimistic decision maker will be with the attention on downside risks.

\section{Equilibrium Analysis under Mean- CVaR Criterion}

In this section, port decides equilibrium loan-to-value ratio $\lambda^{*}$ to maximize the expected utility. The objective function is formulated as follows:

$$
\max _{\lambda} U[\pi(\lambda)]=\max _{\lambda}\left\{\Phi(\lambda)=\theta E[\pi(\lambda)]+(1-\theta) \operatorname{CVaR}_{\eta}[\pi(\lambda)]\right\}
$$

According to the profit and CVaR function, we have:

$$
\begin{aligned}
& E[\pi(\lambda)]=\lambda w q\left(I_{r}-I_{0}\right) T+\left(H-C_{h}\right)+\left(S-C_{s}\right) q T-(p-k) \int_{0}^{Z_{0}} F(x) d x \\
& \operatorname{CVaR}_{\eta}[\pi(\lambda)]=v-\frac{1}{\eta} \int_{Z_{0}}^{A}\left\{v-\left[\begin{array}{l}
\lambda w q\left(I_{r}-I_{0}\right) T+\left(H-C_{h}\right) q \\
+\left(S-C_{s}\right) q T
\end{array}\right]\right\}^{+} f(x) d x \\
& -\frac{1}{\eta} \int_{0}^{Z_{0}}\left\{v-\left[(p-k) x+k q-\lambda w q\left(1+I_{0} T\right)-C_{h} q-C_{s} q T\right]\right\}^{+} f(x) d x
\end{aligned}
$$

Set $k q-\lambda w q\left(1+I_{0} T\right)-C_{h} q-C_{s} q T=\gamma_{1}$,

$\lambda w q\left(I_{r}-I_{0}\right) T+\left(H-C_{h}\right) q+\left(S-C_{s}\right) q T=\gamma_{2}$,

Scenariol: if $v<\gamma_{1}$, we have $C \operatorname{VaR}_{\eta}[\pi(\lambda)]=v$, hence, $\frac{\partial \Phi(\lambda, v)}{\partial v}=1-\theta>0$ holds.

Scenario2: if $v>\gamma_{2}$, we have $\frac{\partial \Phi(\lambda, v)}{\partial v}=(1-\theta)\left(1-\frac{1}{\eta}\right)<0$.

Scenario3: if $\gamma_{1} \leq v \leq \gamma_{2}$,

we have

$\operatorname{CVaR}_{\eta}[\pi(\lambda)]=v-\frac{1}{\eta} \int_{0}^{v-\left[k q-\lambda w q\left(1+l_{0} T\right)-C_{h} q-C_{q} q T\right]}(p-k) F(x) d x$

Taking the first-order derivative of $\Phi(\lambda, v)$ with respect to $v$ in Equation (2), it follows that $\frac{\partial \Phi(\lambda, v)}{\partial v}=(1-\theta)\left\{1-\frac{1}{\eta} F\left[\frac{v-\left(k q-\lambda w q\left(1+I_{0} T\right)-C_{h} q-C_{s} q T\right)}{p-k}\right]\right\}$.

If ${ }^{v=\gamma_{1}}$, it's obvious that $\frac{\partial \Phi(\lambda, v)}{\partial v}=1-\theta>0$. If ${ }^{v=\gamma_{2}}$, we have $\frac{\partial \Phi(\lambda, v)}{\partial v}=(1-\theta)\left[1-(1 / \eta) F\left(Z_{0}\right)\right]$. 
We can draw from the above analysis that there are two cases for the objective $\max _{\lambda} U[\pi(\lambda)]$ when ${ }^{v=\gamma_{2}}$ because it is uncertain that whether $\frac{\partial \Phi(\lambda, v)}{\partial v}$ is positive or negative:

(1) If $^{1-(1 / \eta) F\left(Z_{0}\right) \leq 0}$,

let $v^{*}$ satisfies

$$
1-(1 / \eta) F\left[\frac{v^{*}-\left(k q-\lambda w q\left(1+I_{0} T\right)-C_{h} q-C_{s} q T\right)}{p-k}\right]=0
$$

the equilibrium $v^{*}$ can be obtained as: $v^{*}=(p-k) F^{-1}(\eta)+\left[k q-\lambda w q\left(1+I_{0} T\right)-C_{h} q-C_{s} q T\right]$. Substitute $v^{*}$ into $\operatorname{CVaR}_{n}[\pi(\lambda)]_{\text {in scenario3 } 3 \text { and then substitute the new }}$ $\mathrm{CVaR}_{n}[\pi(\lambda)]$ into the utility function in Equation (2), the utility function can be rewritten as:

$$
\begin{aligned}
& \Phi\left(\lambda, v^{*}\right)=\theta\left[\lambda w q\left(I_{r}-I_{0}\right) T+\left(H-C_{h}\right) q+\left(S-C_{s}\right) q T-(p-k) \int_{0}^{Z_{0}} F(x) d x\right] \\
& +(1-\theta)\left\{(p-k) F^{-1}(\eta)+\left[\begin{array}{l}
k q-\lambda w q\left(1+I_{0} T\right) \\
-C_{h} q-C_{s} q T
\end{array}\right]-\frac{1}{\eta} \int_{0}^{F^{-1}(\eta)}(p-k) F(x) d x\right\}
\end{aligned}
$$

Taking the first-order derivative of $\Phi\left(\lambda, v^{*}\right)$ with respect to $\lambda$ in Equation (3) and let $\frac{\partial \Phi\left(\lambda, v^{*}\right)}{\partial \lambda}=0$, we have $\theta w q\left(I_{r}-I_{0}\right) T-\theta w q\left(1+I_{r} T\right) F\left(Z_{0}\right)-(1-\theta) w q\left(1+I_{0} T\right)=0 \quad$. It follows that $F\left(Z_{0}^{*}\right)=1-\frac{1+I_{0} T}{\theta\left(1+I_{r} T\right)}$. Let ${ }^{1-\frac{1+I_{0} T}{\theta\left(1+I_{r} T\right)}=\Omega_{1}}$, we get $\lambda_{1}^{*}=\frac{(p-k) F^{-1}\left(\Omega_{1}\right)-(H q+S q T-k q)}{w q\left(1+I_{r} T\right)}$

(2) If $1-(1 / \eta) F\left(Z_{0}\right)>0, v^{*}=\lambda w q\left(I_{r}-I_{0}\right) T+\left(H-C_{h}\right) q+\left(S-C_{s}\right) q T$. Substitute $v^{*}$ into $\mathrm{CVaR}_{\eta}[\pi(\lambda)]$ in scenario3 and then substitute the new $\mathrm{CVaR}_{\eta}[\pi(\lambda)]$ into Equation (2), we get:

$$
\begin{aligned}
& \Phi\left(\lambda, v^{*}\right)=\lambda w q\left(I_{r}-I_{0}\right) T+\left(H-C_{h}\right) q+\left(S-C_{s}\right) q T \\
& -(p-k)\left[\theta+\frac{(1-\theta)}{\eta}\right] \int_{0}^{Z_{0}} F(x) d x
\end{aligned}
$$

Taking the first-order derivative of $\Phi\left(\lambda, v^{*}\right)$ with respect to ${ }^{\lambda}$ in Equation (4) and let $\frac{\partial \Phi\left(\lambda, v^{*}\right)}{\partial \lambda}=0$, we get $w q\left(I_{r}-I_{0}\right) T-\left[\theta+\frac{(1-\theta)}{\eta}\right] w q\left(1+I_{r} T\right) F\left(Z_{0}\right)=0$ $F\left(Z_{0}^{*}\right)=\frac{\eta\left(I_{r}-I_{0}\right) T}{(1-\theta+\eta \theta)\left(1+I_{r} T\right)}$

It follows that obtain $^{*} Z_{0}^{*}=F^{-1}\left(\Omega_{2}\right)$ and thus $\lambda_{2}^{*}=\frac{(p-k) F^{-1}\left(\Omega_{2}\right)-(H q+S q T-k q)}{w q\left(1+I_{r} T\right)}$.

\section{Numerical Analysis}

In order to demonstrate the impact of decision preference, risk aversion factor and port logistics service charge on equilibrium loan-to-value ratio, this paper performs some numerical experiments. The values of parameters are displayed in Table 1. It is assumed that the random demand of collaterals $x$ follows uniform distribution $U(0,200)$. Moreover, we set the initial values of $\theta$ and $\eta$ are 0.5 and 0.75 respectively. Bring the above parameters into the model and get that the optimal loan-to-value ratio is 0.576 . The applicability and rationality of the model is verified.

Table1. The initial values of parameters

\begin{tabular}{|c|c|c|c|c|c|c|c|c|c|c|}
\hline$q$ & $w$ & $p$ & $k$ & $T$ & $I_{r}$ & $I_{0}$ & $H$ & $C_{h}$ & $S$ & $C_{s}$ \\
\hline 90 & 100 & 200 & 60 & 2 & 0.05 & 0.02 & 11 & 6 & 0.1 & 0.06 \\
\hline
\end{tabular}

\subsection{The influence of decision preference coefficient on loan-to-value ratio}

Figure.1 depicts the impact of decision preference coefficient ${ }^{\theta}$ on equilibrium loan-to-value ratio $\lambda^{*}$ with the assumption of $\theta \in(0,1)$.The result shows that the decision preference coefficient has a positive impact on loan-tovalue ratio. The more importance port attaches to the expected profit which shows optimistic attitude towards the profit, the more inclined the lender is to provide a high loan-to-value ratio.

\subsection{The influence of risk aversion factor on loan- to-value ratio}

Figure. 2 captures the positive relationship between the risk aversion factor $\eta$ on equilibrium $\lambda^{*}$ with the assumption of $\eta \in(0,1]$. Given that the smaller the value of $\eta$, the higher the risk aversion degree, the result demonstrates that port will be conservative and cautious in offering loans with the growth of risk-averse attitude due to loss avoidance.

\subsection{The influence of port logistics service charge on loan-to-value ratio}

Figure.3 illustrates the impact of port logistics service charge $H$ on equilibrium loan-to-value ratio $\lambda^{*}$ with the assumption of $H \in[7,22]$. There is a negative correlation between service charge and loan-to-value ratio. The logistics financing service is an important measure to extend traditional warehousing and transportation business and increase returns. Especially in the condition of depressed shipping market, the enthusiasm of port to develop high value-added services will rise. When the service charge goes up, the cost of trade increases along with the risk of default on loans. Port shall gradually be cautious in allocating loan quotas.

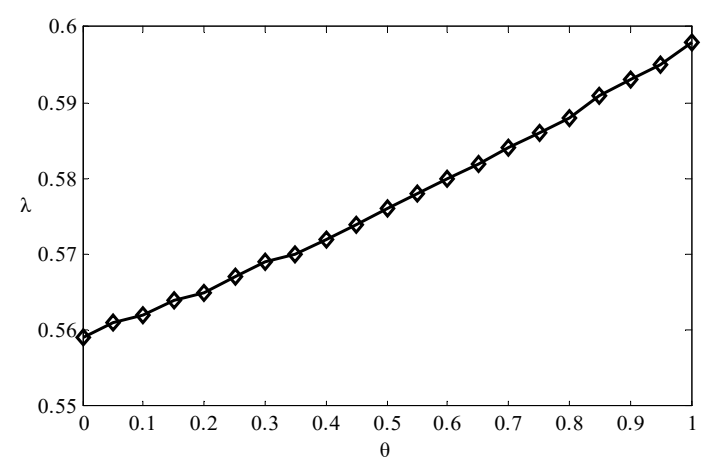

Fig 1. The impact of $\theta_{\text {on }}^{\lambda}$ 


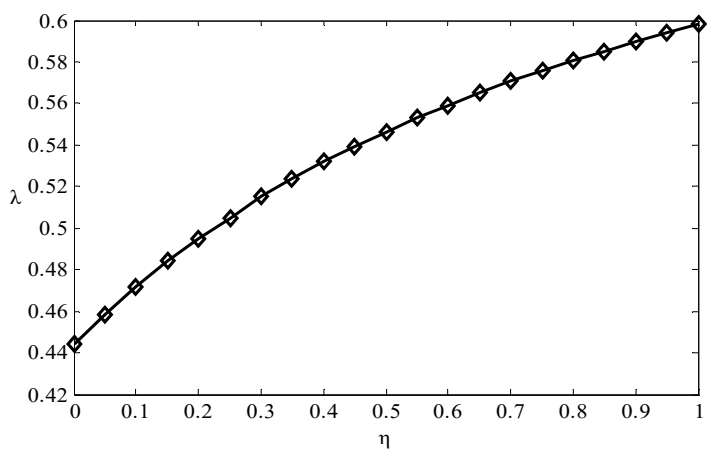

Fig 2. The impact of ${ }^{\eta}$ on $\lambda$

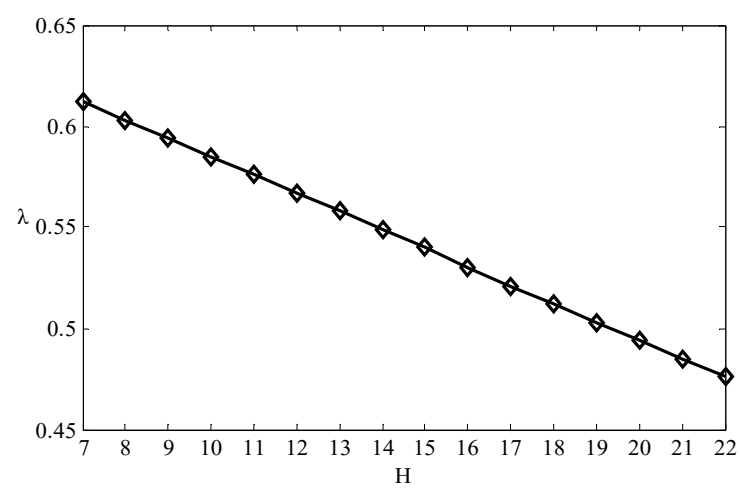

Fig 3. The impact of $\mathrm{H}_{\text {on }} \lambda$

\section{Conclusions}

This paper aims at the inventory financing services offered by port based on the practices of Chinese ports such as Tianjin Port and Dalian Port. We adopt Mean-CVaR criterion to formulate a trade-off objective function which combines the expected profit and CVaR and derive the equilibrium loan-to-value ratio for port. It is found that the emphasis on expected profit results in a higher loan-tovalue ratio; while the decision focusing on downside risk leads to a lower loan-to-value ratio. The higher the degree of risk aversion, the smaller the loan-to-value ratio is. When the profit margin of traditional port logistics services is compressed, port will strengthen financial services in order to seek new growth point of profit. Port could take advantage of the convergence of capital flow, information flow and logistics to upgrade traditional services and gain more profit.

\section{Acknowledgment}

This work was supported by the National Natural Science Foundation of China (71831002,71672016); The National Key Research and Development Program of the Ministry of Science and Technology (2019YFB1600400); Program for Innovative Research Team in University of Ministry of Education of China (IRT_17R13); the Fundamental Research Funds for the Central Universities (3132020501, 3132019325, 3132019326).

\section{References}

1. Liu, X.L., "Research on logistics service innovation of international major ports under marine economic strategy," Journal of Coastal Research, vol. 115, pp. 283-285, August 2020.

2. Huang, S., Fan, Z.P., and Wang, X.H., "The impact of transportation fee on the performance of capitalconstrained supply chain under 3PL financing service," Computers \& Industrial Engineering, vol.130, pp.358-369, April 2019.

3. Wang, Y., Ma, X.R., "Study on warehousing financing risk-return of supply chain system in chinese ports-hinterland," In: Proceedings of the $5^{\text {th }}$ International Conference on innovation and management. Wuhan. pp. 1551-1559, 2009.

4. Hofmann, E., "Inventory financing in supply chains: a logistics service provider-approach," International Journal of Physical Distribution \& Logistics Management, vol. 39, pp.716-740, 2009.

5. Chen, X.F., Cai, G.S., "Joint logistics and financial services by a 3PL firm," European Journal of Operational Research, vol. 214, pp. 579-587, November 2011.

6. Wang, F., Yang, X., Zhuo, X.P., and Xiong, M.H., "Joint logistics and financial services by a 3PL firm: Effects of risk preference and demand volatility," Transportation Research Part E: Logistics and Transportation Review, vol. 130, pp. 312-328, October 2019.

7. He, J., Jiang, X.L., Wang, J., Zhu, D.L., and Zhen, L., "VaR Methods for the dynamic impawn rate of steel in inventory financing under autocorrelative return," European Journal of Operational Research, vol. 223, pp. 106-115, Novembe 2012.

8. Yan, N.N., Liu, C.Q., Liu, Y., and Sun, B.W., "Effects of risk aversion and decision preference on equilibriums in supply chain finance incorporating bank credit with credit guarantee," Applied Stochastic Models in Business and Industry, vol. 33, pp. 602-625, July 2017.

9. Rockafellar, R.T., and Uryasev, S., "Optimization of Conditional Value-at-Risk," Journal of Risk, vol. 2, pp. 21-41, 2000.

10. Avci, M.G., "Lateral Transshipment and expedited shipping in disruption recovery: A Mean-CVaR approach," Computers \& Industrial Engineering, vol. 130, pp. 35-49, April 2019. 